\title{
Extrafollicular adenomatoid odontogenic tumour
}

\author{
Guru Prasad, ${ }^{1}$ Preeti Nair, ${ }^{1}$ Shaji Thomas, ${ }^{2}$ Harshkant Gharote, ${ }^{1}$ Neha Singh, ${ }^{1}$ Annette Bhambal ${ }^{1}$
}

${ }^{1}$ Department of Oral Medicine and Radiology, People's College of Dental Sciences and Research Centre, Bhopal, Madhya Pradesh, India;

2Department of Oral and Maxillofacial Surgery, People's College of Dental Sciences and Research Centre, Bhopal, Madhya Pradesh, India

Correspondence to Preeti Nair, shajihoss@gmail.com

\section{Summary}

Adenomatoid odontogenic tumour (AOT) is an uncommon, benign tumour that represents $3-7 \%$ of all odontogenic tumours. It is slow growing, occurs twice as common in females and usually in the second decade of life. There are three subclinical types of this tumour with identical histology: follicular type (73\%), extrafollicular variant (24\%) and peripheral form (3\%). Here, the authors have presented two rare cases of extrafollicular varieties of AOT in 25-year-old female patients, of which one was situated in the maxillary canine area and the other one situated in an unusual location of mandibular premolar area. Such lesions may be confused as an odontogenic cyst and should be carefully differentiated from other benign and malignant lesions arising in this region.

\section{BACKGROUND}

The incidence of adenomatoid odontogenic tumours (AOTs) among odontogenic tumours is only $3-7 \%$ of which the extrafollicular variety accounts for about $24 \%$. This report describes two such unique cases of extrafollicular variety of which the second case was located in the mandible which is an atypical location for an AOT.

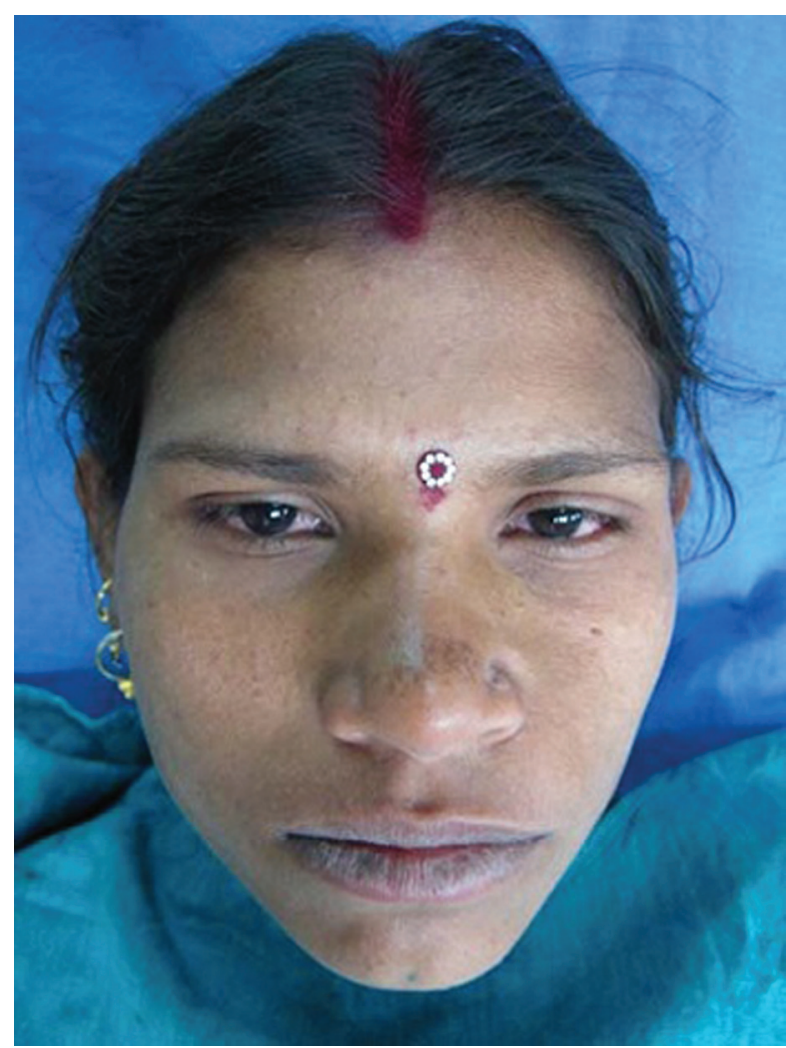

Figure 1 Solitary ovoid swelling present on left middle $1 / 3$ of face.

\section{CASE PRESENTATION}

AOT is a benign (hamartomatous), non-invasive lesion with slow but progressive growth. ${ }^{1}$ These lesions are usually located in the anterior region of maxilla; they normally produce painless swelling. ${ }^{2}$ The cuspid is the tooth most commonly associated with AOT.3 The tumour growth may cause displacement of teeth rather than root resorption. $^{2}$ AOT was first described by Dreibladt, in 1907, as a pseudoadenoameloblastoma. In 1948, Stafne considered it a distinct entity, but it was classified by others as a variant of ameloblastoma. As a result, the lesion is known by many names, including adenoameloblastoma, adenoameloblastic odontoma, epithelial tumour associated with developmental cysts, ameloblastic adenomatoid tumour and adenomatoid or pseudoadenomatous ameloblastoma. Philipsen and Birn proposed the name adenomatoid odontogenic tumour in 1969 and suggested that it not be regarded as a variant of ameloblastoma because of its different behaviour. This term was adopted by the WHO classification in $1971 .{ }^{1}$

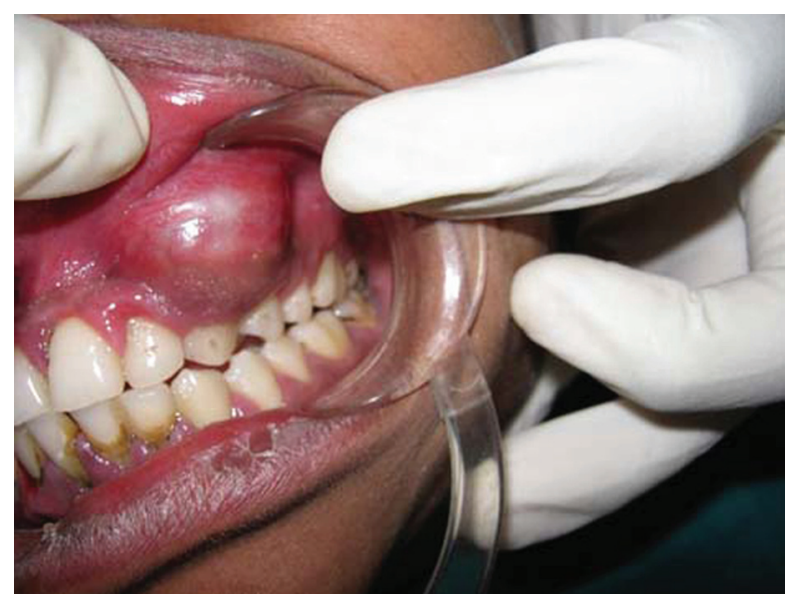

Figure 2 Expansion of the buccal cortex with yielding in some areas. 


\section{BMJ Case Reports}

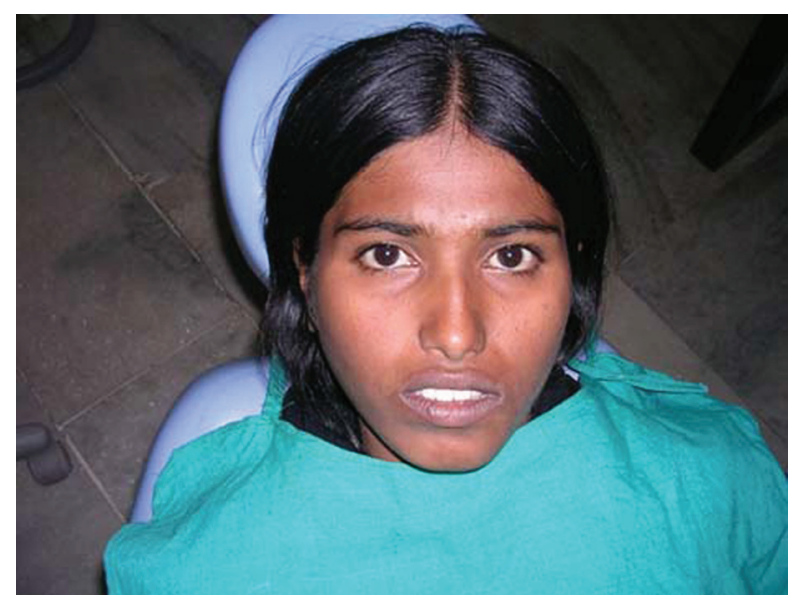

Figure 3 Solitary, diffuse, smooth, bony swelling was present on the left lower half of the face.

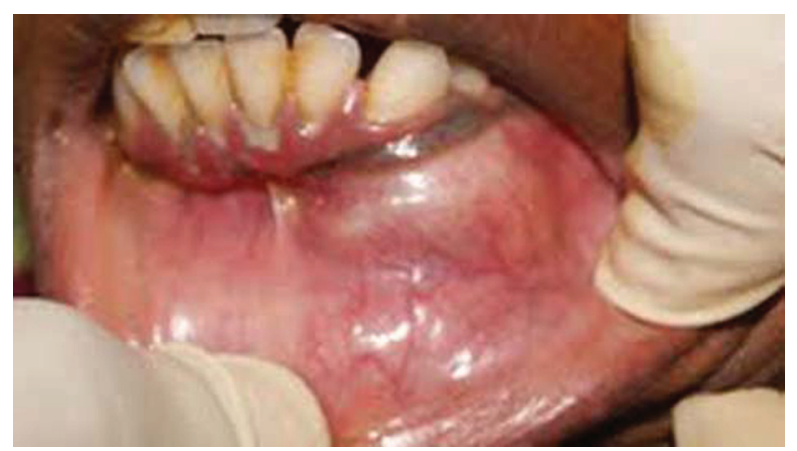

Figure 4 Expansion of the buccal cortex with egg-shell crackling in some areas.

There are three clinical subtypes of AOT, with identical histology: follicular type, the extrafollicular variant and the peripheral form. The follicular type (in $73 \%$ of AOT) is centrally located, with a radiolucent unilocular cystic area associated with an unerupted or impacted tooth (usually canine), simulating the image of a dentigerous cyst. The extrafollicular variant $(24 \%)$ likewise with a central location, but unrelated to any dental structure, and may be confused with periapical cysts and other cystic or tumoral lesions of the maxilla. Finally, the peripheral form is the most infrequent (3\%), affects the gingival mucosa and is often preoperatively classified as a fibrous epulis or gingival fibroma. ${ }^{4}$

\section{Case report 1}

A 25-year-old female reported with swelling in upper front tooth region since 2 years and pain since 1 month. She gave history of trauma to the face 3 years back and noticed a swelling in upper front tooth region which increased in size gradually. Initially, pain was dull but later it became severe. Medical history was unremarkable.

A solitary ovoid swelling was present on left middle 1/3 of face extending superior-inferiorly from ala of nose to left corner of mouth, measuring $3 \mathrm{~cm}$ in size with smooth surface and diffuse margin (figure 1). It was tender and bony hard on palpation. On intraoral examination, a solitary swelling was present on buccal vestibule in relation

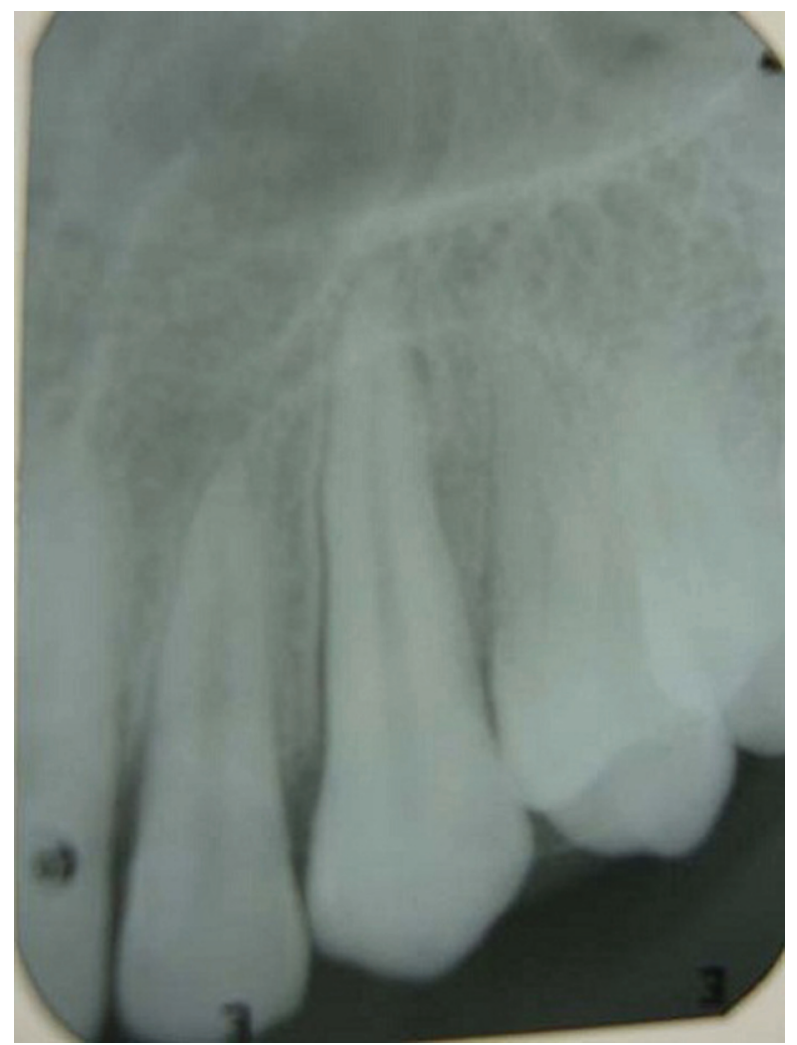

Figure 5 IOPA revealed a well to ill-defined round radiopaque rim overlapping 22, 23, 24.

to 22 , extending up to 24. Expansion of the buccal cortex with yielding in some areas was noted (figure 2). Twentythree was tender to percussion with grade II mobility and was found non-vital on electric pulp testing. The provisional diagnosis of periapical cyst in relation of 23 was put forth.

\section{Case report 2}

A 25-year-old female reported to the department with painless swelling in the lower left front tooth region since 3 months. History revealed a small painless pea-sized swelling in the left lower jaw between two front teeth since 6 months, which had gradually grown to the present size. She also had mild intermittent pain in the left lower canine since 1 week.

A solitary, diffuse, smooth, bony swelling was present on the left lower half of the face which extended anteriorly, from the midline of the mandible to approximately $1.5 \mathrm{~cm}$ posteriorly, up to the angle of the mouth (figure 3). Intraoral examination revealed a well-defined, non-tender, single, oval, bony swelling of size $2 \mathrm{~cm}$ below 32, 33 and 34 buccally in the alveolar bone. There was expansion of the buccal cortex with egg-shell crackling in some areas (figure 4). All the teeth in the vicinity of the lesion tested vital. The provisional diagnosis of lateral periodontal cyst in relation with 33 was put forth.

\section{INVESTIGATIONS}

\section{Case report 1}

Intraoral periapical radiograph (IOPA) revealed a well to ill-defined round radiopaque rim overlapping 22, 23, 24 


\section{BMJ Case Reports}

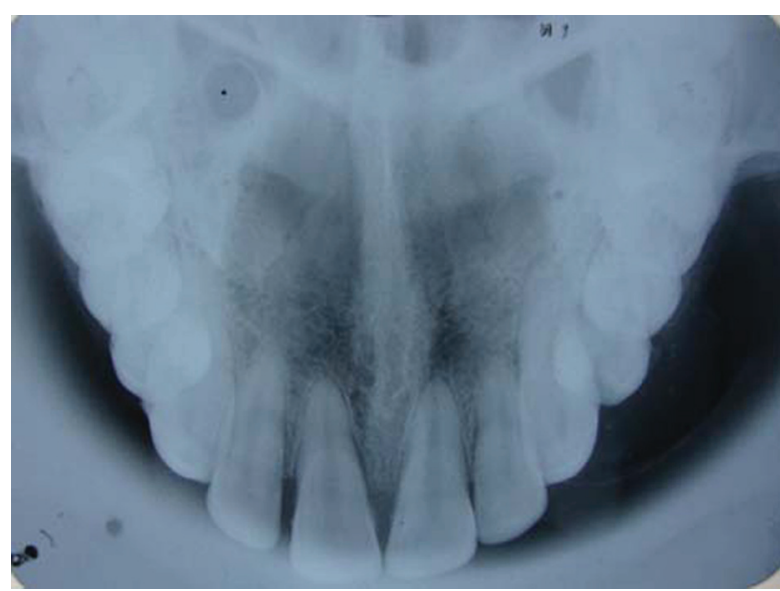

Figure 6 Occlusal view showed expansion of buccal cortical plate with multiple foci of calcification.

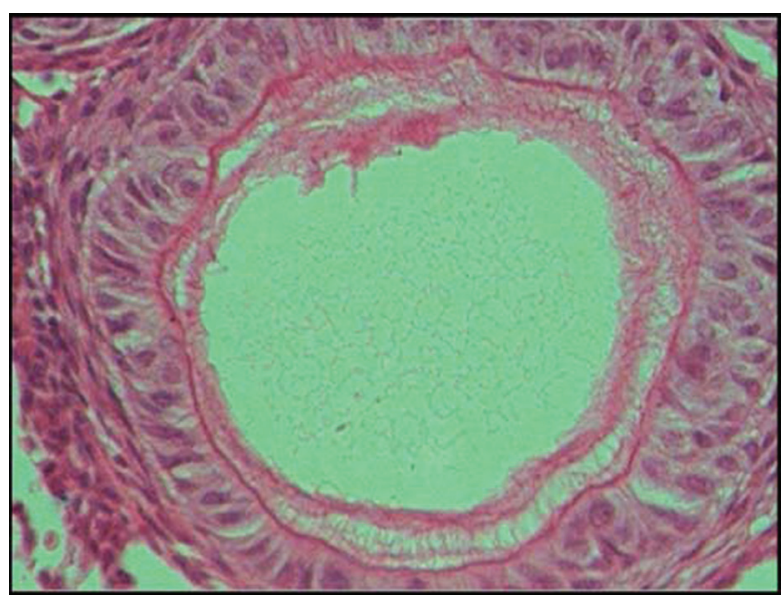

Figure 8 Duct-like pattern was seen lined by columnar cells, some of which enclose eosinophilic material.

extending from mesial surface of 22 to distal surface of 24 and widening of periodontal ligament space on mesial surface with 23 (figure 5). Occlusal view showed expansion of buccal cortical plate with multiple foci of calcification (figure 6).

Fine needle aspiration cytology revealed $1 \mathrm{ml}$ bloodtinged fluid. Surgical enucleation was carried out under local anaesthesia. Histopathological examination showed a thick capsule lined by odontogenic epithelium composed largely of spindle-shaped cells arranged in the form of sheets with whorling and at the periphery in thin cords (figure 7).

Duct-like pattern was seen lined by columnar cells, some of which enclose eosinophilic material (figure 8). One focus showed presence of spherical calcification. The dense connective tissue showed haemorrhage and scattered chronic inflammatory cells, which was suggestive of extrafollicular AOT.

\section{Case report 2}

Intraoral radiograph and orthopantomograph revealed a well-defined radiolucent lesion with corticated margins present between 33 and 34 . The roots of 33 and 34 were displaced mesially and distally, respectively (figures 9 and

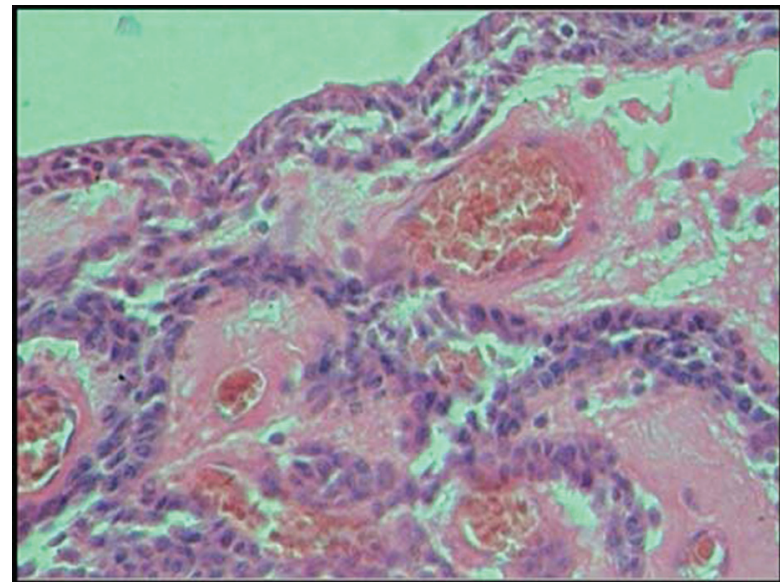

Figure 7 Thick capsule lined by odontogenic epithelium composed largely of spindle-shaped cells arranged in the form of sheets with whorling and at the periphery in thin cords.

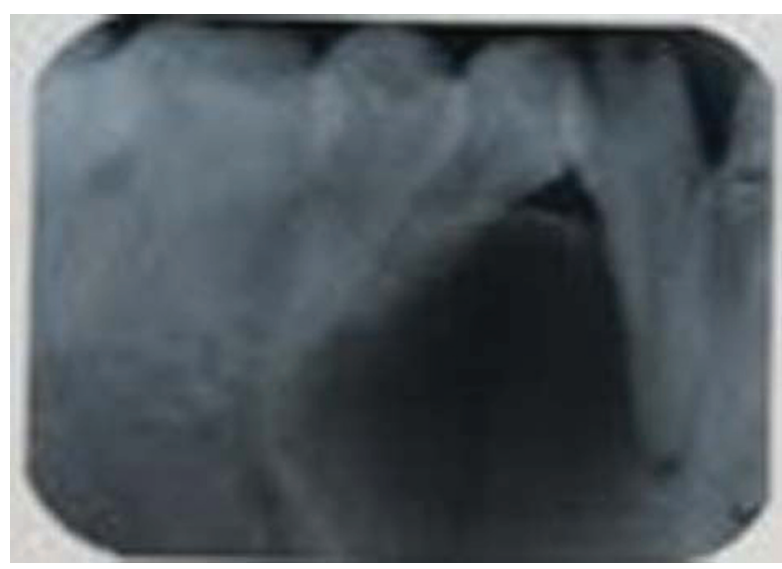

Figure 9 IOPA revealed a well-defined radiolucent lesion with corticated margins present between 33 and 34 .

10). Occlusal view showed expansion of buccal cortical plate with multiple foci of calcification (figure 11).

As with the previous case, fine needle aspiration cytology revealed blood-tinged fluid of about $1 \mathrm{ml}$. The lesion was enucleated and sent for histopathological evaluation. The report stated a thick connective tissue capsule lined by two to three layered odontogenic epithelium with sheets and whorls of spindle-shaped cells interspersed with eosinophilic droplets along with arrangement and numerous spherical calcifications. The connective tissue showed interconnecting strands of odontogenic epithelium (figure 12). The final diagnosis was given as extrafollicular AOT in the left parasymphyseal region.

\section{DIFFERENTIAL DIAGNOSIS}

\section{Case report 1}

Differential diagnosis of calcifying odontogenic cyst, AOT and globulomaxillary cyst were considered.

\section{Case report 2}

Differential diagnosis of collateral variety of odontogenic keratocyst, dentigerous cyst (collateral/associated with 
supernumerary teeth), calcifying odontogenic cyst, calcifying epithelial odontogenic tumour, central giant cell granuloma and extrafollicular variety of AOT were considered.

\section{TREATMENT}

Enucleation of both the lesions had been done and no recurrence has been reported till date.

\section{OUTCOME AND FOLLOW-UP}

The patients are currently under regular follow-up.

\section{DISCUSSION}

AOT is a rare odontogenic tumour which is often misdiagnosed as odontogenic cyst. ${ }^{5}$ The tumour was first reported by Harbitz in 1915 under the name of cystic adamantoma. A multitude of authors during the early 1900s has been given credit to researchers like Steensland, Dreybladt, and James and Forbes for reporting the first case of AOT. ${ }^{6}$ AOT are less frequent than odontoma, cementoma, myxoma and ameloblastoma. ${ }^{7}$ It has been suggested by some authorities that this tumour may be a hamartoma rather than a true neoplasm, due to the limited size and to the lack of recurrence of most cases. ${ }^{8}$ The pathogenesis of AOT is unknown. The cells of origin was suggested as entrapped epithelium in the line of embryonal fusion by Stafne (1948); odontogenic epithelium, outer enamel epithelium, inner enamel epithelium, cell rests of Malassez, dental laminae or its remnants. ${ }^{9}$ Various authors have reported these tumours as intraoral and extraoral swellings in the maxilla which is similar to case 1 . Although few large lesions have been reported, the usual size of the lesion is $1.5-3 \mathrm{~cm}$ and this matches with the size of the lesions presented here. Clinical, radiographic and macroscopic findings in the present cases are consistent with descriptions of the lesion in the dental literature.

Yilmaz et al presented an AOT causing jaw swelling in the mandibular anterior region between 32 and 41 which was painless, bony hard and non-tender with no history of trauma, pain, discharge or any other symptoms. These findings were consistent with that of the second case reported here. ${ }^{10}$

Radiographically, central AOT presents as well demarcated, almost always unilocular radiolucency that generally exhibits a smooth corticated border and with faintly detectable radiopaque foci within the radiolucent lesion. ${ }^{8}$ In the first case, the lesion was radiolucent with sclerotic border and fine calcifications and in the second case, the radiographic findings showed circumscribed radiolucent area with fine calcifications involving the teeth 32 to 41 with associated displacement and thinned cortical layer.

The AOT is a well-defined lesion that is usually surrounded by a thick, fibrous capsule. ${ }^{11}$ WHO has described the histologic features of the tumour as follows: 'A tumor of odontogenic epithelium with duct like structures and with varying degree of inductive changes in the connective tissue. The tumor may be partly cystic and in some cases the solid lesion may be present only as masses in the wall of a large cyst. It is generally believed that the lesion is not a neoplasm'. The histologic appearance of all variants is identical and exhibits remarkable consistency. At low magnification, the most striking pattern is that of various sizes

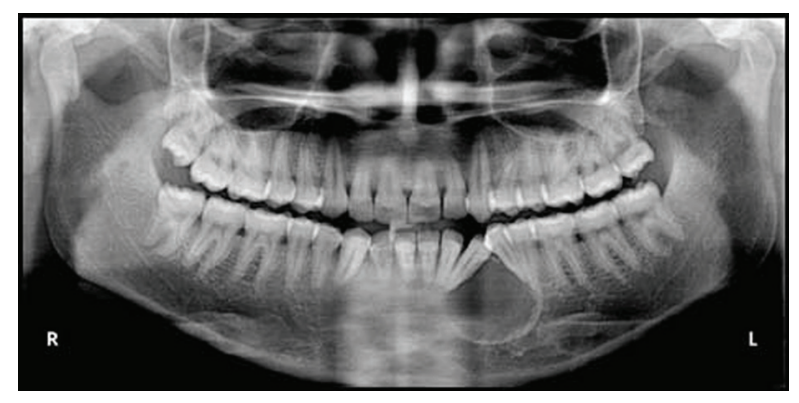

Figure 10 Orthopantomograph revealed a well-defined radiolucent lesion with corticated margins present between 33 and 34 .

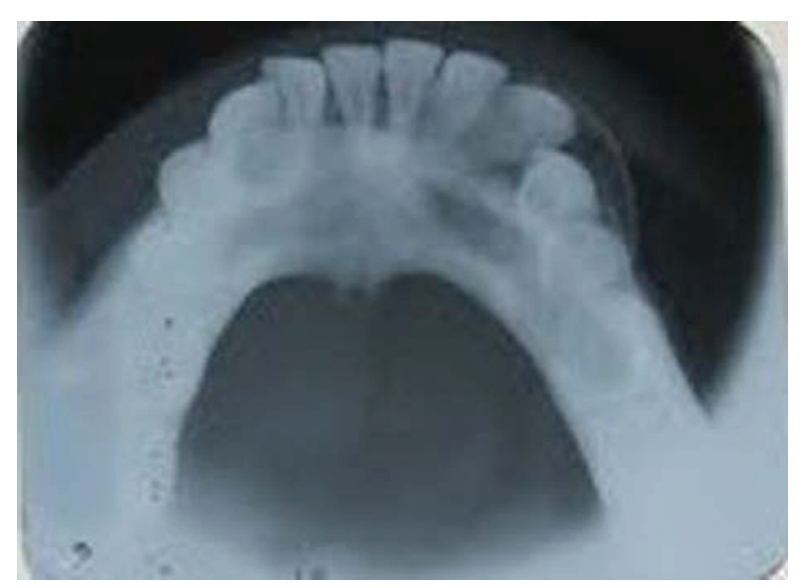

Figure 11 Occlusal view showing expansion of buccal cortical plate with multiple foci of calcification.

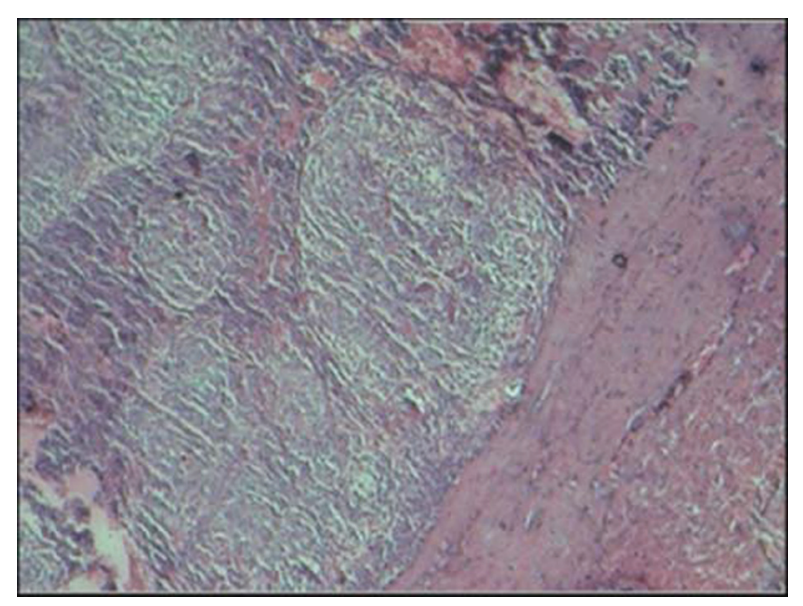

Figure 12 Thick connective tissue capsule lined by two to three layered odontogenic epithelium with sheets and whorls of spindleshaped cells interspersed with eosinophilic droplets along with arrangement and numerous spherical calcifications.

of solid nodules of columnar or cuboidal epithelial cells forming nests or rosette-like structures with minimal stromal connective tissue. Between the epithelial cells of the nodules and in the centre of the rosette-like configuration is found eosinophilic amorphous material, often described as tumour deposits. ${ }^{1}$ Conspicuous within the cellular areas are structures of tubular or duct-like appearance, which 


\section{BMJ Case Reports}

was consistent with the histopathological finding of these two cases.

Treatment consists of surgical enucleation and no reoccurrence has been reported even after incomplete removal, its main difference from ameloblastoma. ${ }^{12}$ Giansanti et al reported that the AOT was a completely benign tumour which never recurred once removed. ${ }^{3}$ AOT treatment is simple enucleation and no recurrence has been reported even after incomplete removal - in the literature.

\section{Learning points}

- AOT can mimick periapical cyst as in the case 1 and lateral periodontal cyst in the case 2 .

- AOT may confuse diagnosis during clinical examination and must be considered in the differential diagnosis of painless swelling present anteriorly in both upper and lower jaw.

- The present cases illustrate the clinicopathological characteristic of the extrafollicular variety of AOT.

\section{REFERENCES}

1. Batra P, Prasad S, Parkash H. Adenomatoid odontogenic tumour: review and case report. J Can Dent Assoc 2005; 71:250-3.

2. Sato D, Matsuzaka K, Yama M, et al. Adenomatoid odontogenic tumor arising from the mandibular molar region: a case report and review of the literature. Bull Tokyo Dent Coll 2004;45:223-7.

3. Dayi E, Gürbüz G, Bilge OM, et al. Adenomatoid odontogenic tumour (adenoameloblastoma). Case report and review of the literature. Aust Dent $J$ 1997:42:315-18.

4. Vera Sempere FJ, Artes Martinez MJ, Sirera BV, et al. Follicular adenomatoid odontogenic tumor: immunohistochemical study. Med Oral Patol Oral Cir Bucal 2006;11:305-8.

5. Handschel JG, Depprich RA, Zimmermannet AC, et al. Adenomatoid odontogenic tumor of the mandible: review of the literature and report of a rare case. Head Face Med 2005:1:3

6. Swasdison S, Dhanuthai K, Jainkittivong A, et al. Adenomatoid odontogenic tumors: an analysis of 67 cases in a Thai population. Oral Surg Oral Med Oral Pathol Oral Radiol Endod 2008;105:210-15.

7. Anand Kumar C, Reddy J, Gupta S, et al. An usual site of AOT presenting as periapical cyst. A rare case report. JIAOMR 2010;22:39-41.

8. Shafer HL. Textbook of Oral Pathology. Fifth edition. Mosby, PA: Elsevier Publication 2006:395.

9. Arati C, Vilas N. An unusual case of a large adenomatoid odontogenic tumor of maxilla. JIAOMR 2007;19:280-3.

10. Yilmaz N, Acikgoz A, Celebi N, et al. Extrafollicular adenomatoid odontogenic tumor of the mandible: report of a case. Eur J Dent 2009:3:71-4.

11. Neville B, Damm D, Allen C, et al. Oral and Maxillofacial Pathology. Second edition. Philadelphia, PA: Elsevier Publication 2002:621.

12. Yavas $\mathbf{F}$, Demiryant $M$, Arinci $A$, et al. A recurrent adenomatoid odontogenic tumor case report. Turk Patoloji Dergisi 1990;6-2:22-5

Patient consent Obtained.

This pdf has been created automatically from the final edited text and images.

Copyright 2011 BMJ Publishing Group. All rights reserved. For permission to reuse any of this content visit

http://group.bmj.com/group/rights-licensing/permissions.

BMJ Case Report Fellows may re-use this article for personal use and teaching without any further permission.

Please cite this article as follows (you will need to access the article online to obtain the date of publication).

Prasad G, Nair P, Thomas S, Gharote H, Singh N, Bhambal A. Extrafollicular adenomatoid odontogenic tumour. BMJ Case Reports 2011;

10.1136/bcr.03.2011.3963, date of publication

Become a Fellow of BMJ Case Reports today and you can:

- Submit as many cases as you like

- Enjoy fast sympathetic peer review and rapid publication of accepted articles

- Access all the published articles

- Re-use any of the published material for personal use and teaching without further permission

For information on Institutional Fellowships contact consortiasales@bmjgroup.com

Visit casereports.bmj.com for more articles like this and to become a Fellow 